\title{
РЕСУРСНЫЙ ПОДХОД К ПСИХОЛОГИЧЕСКОМУ КАПИТАЛУ И ОСОЗНАННОЙ САМОРЕГУЛЯЦИИ ЧЕЛОВЕКА
}

Моросанова В.И. (ФГБНУ «Психологический институт Российской академии образования», Москва, Россия) Аванесян Г.М. (Ереванский государственный университет, Ереван, Армения) morosanova@mail.ru avanesyanh@ysu.am

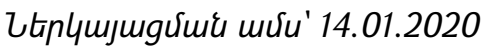

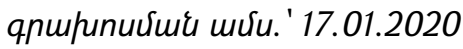

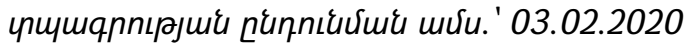

Статья посвящена ресурсному подходу к исследованию психологического капитала и осознанной саморегуляции человека. Основные его положения были сформулированы ранее (В.И. Моросанова, 2014, 2017, 2019), и настоящая статья имеет целью раскрыть ресурсную природу этих важнейших для достижения профессиональных и учебных целей феноменов. В контексте проблемы проанализированы основные аспекты исследования психологического капитала. Сделан вывод о том, что осознанная саморегуляция является метасистемой универсальных и специальных ресурсов человека, позволяющих вносить вклад в продуктивные аспекты достижения целей, а также активизировать резервы психологического капитала для достижения разнообразных задач жизнедеятельности.

Ключевые слова: психологический капитал, ресурсный подход, осознанная саморегуляция, учебная, профессиональная деятельность.

В современной науке интенсивно идёт разработка проблемы человеческого и психологического капитала. Приобретают особую актуальность исследования психологического капитала с включением широкого спектра личностных и субъектных качеств, которые могут оказывать значимое влияние на результаты жизнедеятельности. В.М. Моросанова в своих научных работах писала о том, что в широком понимании с помощью термина «ресурсы» всякий предмет, процесс и организм может рассматриваться в инструментальной функции, а именно, как обладающий изменчивым и в тоже время ограниченным запасом возможностей для решения тех или иных задач [11]. Проблема заключается в том, что это понимание ресурсов непротиворечиво применимо в экономике и близких к ней областях науки и практики, а использование данного термина в психологии, несмотря на его распространённость, весьма неоднозначно $[2,16,18]$. 
«Ресурсы» в психологии - это психологические средства осознанного решения определённой задачи. Например - это любые внутренние и внешние условия, реальные и идеальные объекты, индивидуальные качества, отношения, установки, ценности, которые субъект создаёт или вовлекает, использует для решения собственных задач и достижения значимых целей [3]. Здесь хотелось бы уточнить, что, любые свойства и отношения человека могут быть им осознанно использованы, если ему это необходимо, но только если их инструментальные возможности способствует решению субъектно принятой задачи. Решением данной проблемы является разделение ресурсов на универсальные и специальные в соответствии с целью человека, условиями ее достижения и решением соответствующих цели конкретных задач. Именно это понимание имплицитно содержится в понятии ресурсов профессиональной и учебной деятельности.

Встает вопрос, можем ли мы говорить о ресурсах деятельности вообще. Или еще более широко - о психологических ресурсах человека. Утвердительный ответ на этот вопрос, с нашей точки зрения, связан с признанием существования универсальных ресурсов, т.е. психологических средств, необходимых для успешного достижения целей в любом виде деятельности.

Мы определяем психологические ресурсы через свойства ресурсности. Анализ литературы показал, что такими свойствами являются возможность их накопления, расходования и восстановления.

Феноменология исследований психологического капитала выводит нас на более широкую проблему психологического ресурса и потенциала человека. С нашей точки зрения, необходимо различать эти понятия с тем, чтобы через их призму рассматривать природу психологического капитала субъекта. Психологический потенциал, с точки зрения ресурсного подхода - это совокупность накопленных в опыте компетенций, и присущих индивидуальности внутренних резервов, которые латентно существуют и могут осознаваться при определённых условиях. Д.А. Леонтьев, анализируя связь личностного потенциала с психологическим капиталом пишет: «Капитал как экономическая категория обозначает ресурсы, которые вкладываются, принося прибыль, но сами не расходуются. У нас не становится меньше резилентности, меньше самоэффективности или меньше управления вниманием; наоборот, все эти ресурсы умножаются. Но где в этой модели инвестор, тот, кто управляет капиталом?» [8, с. 26]. В этой логике мы переходим к понятию саморегуляции, которая может быть, в одних ситуациях потенциалом, а в других - значимым ресурсом. Наши исследования показали, что все зависит от задачи, для решения которой она используется.

Рассмотрим френомен осознанной саморегуляции как ресурс успешности профессиональной и учебно-профессиональной деятельности. Психическая 
саморегуляция - это многоуровневая и динамическая система процессов, состояний и свойств, являющаяся инструментом инициации и поддержания произвольной активности. Система саморегуляции (СР) имеет свои проекции на различные виды активности человека. Их специфичность определяется различными психическими средствами: когнитивными, личностными, темпераментальными и т.д., используемыми для осуществления регуляции [10, 12, 31].

Осознанная саморегуляция - это высший уровень психической саморегуляции. Являясь принципиально рефлексивным психологическим инструментом человека в организации своей активности, она реализует эту активность посредством актуализации различных первичных психических процессов и состояний (когнитивных и личностных). Согласно нормативной модели осознанной СР [5], основными структурными ее компонентами являются: планирование целей, моделирование значимых условий их достижения, программирование последовательности и способов действий, оценивание и корректирование их результатов. Нетрудно заметить, что этот операциональный уровень саморегуляции является, по существу, когнитивным и во многом аналогичен представлениям о саморегуляции в структурных теориях когнитивной психологии. Личностный уровень осознанной саморегуляции представлен инструментальными регуляторно-личностными свойствами, такими как гибкость, надежность, ответственность, инициативность, рефлексивность, за которыми стоят индивидуально-типические стратегии поведения [11]. Общее развитие осознанной СР зависит, с нашей точки зрения, как от когнитивного, так и от личностного уровня саморегуляции. От степени совершенства процессов саморегуляции зависит успешность, надёжность, продуктивность, конечный результат действий по достижению цели.

Рассмотрим ресурсную природу саморегуляции через основные свойства ресурсности: целесообразности, инструментальности, осознанности, распределяемости, истощаемости, восстанавливаемости. Теоретический и эмпирический анализ показал, что осознанной саморегуляции присущи все основные характеристики ресурсности [11]. Она целесообразна, так как именно цель является для неё системообразующим фрактором; инструментальна, так как является психологическим средством достижения цели; потенциально осознаваема как в отношении собственно регуляторных процессов, так и внутренних и внешних средств ее реализации; распределяема [6,21]; расходуема $[2,5,16]$. Истощаемость регуляторных ресурсов также была показана в исследованиях роли осознанной СР в преодолении стрессовых функциональных состояний [7, 22, 31].

Несомненное не только научное, но и прикладное значение имеет выявление универсальных и специальных регуляторных ресурсов, которые имеют принципиально сходное строение. При этом универсальный ресурс в 
большей степени отражает уровень развития саморегуляции и совокупность накопленных в опыте регуляторных навыков достижения разнообразных целей. В то время как специальный регуляторный ресурс по структуре и содержанию реализующих его регуляторных компетенций соответствует лишь определённому классу целей или даже одной конкретной задаче. Так, от общего уровня развития осознанной саморегуляции, как универсального ресурса зависят общие показатели успешности учебной деятельности, в то время академическая успеваемость по различным учебным дисциплинам в большей степени определяется более частными специальными регуляторными ресурсами. Исследования показали, что общее развитие осознанной саморегуляции является универсальным ресурсом академической успеваемости и успешности сдачи выпускных экзаменов [14, 15].

Аналогично можно говорить о существовании универсальных и специальных ресурсов успешности различных видов профессиональной деятельности. Так, для профессий высоко риска (спасатели, пожарные, моряки, пилоты летательных аппаратов, спортсмены) профессионально-значимым универсальным ресурсом является развитие не только общего уровня саморегуляции, но и развитие регуляторной надёжности, как устойчивости саморегуляции в психологически напряжённых условиях. Выделяются также специальные регуляторные ресурсы, вносящие наибольший вклад в успешность различных видов профессиональной деятельности. Например, моделирование значимых условий и программирование действий у спасателей, моряков и пожарников [4], механизмы биологической обратной связи в моделирующем эксперименте в спорте [1], планирование целей и программирование действий у педагогов [17]. У офицеров космических войск, наиболее мотивированных на продолжение профессиональной деятельности, специальным регуляторным ресурсом также является моделирование значимых условий достижения целей [17].

Мы полагаем, что осознанная СР носит черты метасистемы психологических ресурсов выдвижения целей и управления их достижением. В наших многочисленных исследованиях было теоретически обоснованно и эмпирически подтверждено, что от развития осознанной саморегуляции зависит успешность достижения цели в самых разных видах учебной и профессиональной деятельности, и обеспечение их психологического благополучия [13]. Регуляторные ресурсы не только непосредственно влияют на продуктивные аспекты деятельности, но и являются медиаторами, опосредствующими вклад в них когнитивных и личностных особенностей $[11,29,30]$.

Масштабное изучение СР в учебной деятельности способствовало появлению в западной психологии понятия self-regulated learning (SRL). Предложенный конструкт позволял исследовать взаимовлияние регуляторных, когнитивных, мотивационных и ситуационных фракторов на успешность 
учебной деятельности [23]. Показано, что психологической основой овладения различными видами учебной деятельности и академической успешности является сформированность психической $\mathrm{CP}(\mathrm{SR})[34,41]$. В учебной деятельности наличие предельно высокого регуляторного ресурса не является типичным и необходимым для успешного обучения в школе и вузе. Наши многочисленные исследования осознанной СР учебной деятельности показали, что высокое гармоничное развитие осознанной саморегуляции достижения учебных целей вносит значимый вклад (наряду с мотивацией и когнитивноинтеллектуальными особенностями) в академическую успешность. В то же время, условием эффективности и надежности обучения является не только и не столько гармоничность развития стилевых особенностей СР учебной деятельности (как компонентов универсального ресурса), сколько формирование эфффективного регуляторного стиля как специальной компетентности и основы специального регуляторного ресурса. Такой стиль может быть сформирован и на основе акцентуированных регуляторных профилей, и не только при высоком, но и при среднем уровне СР. Главное - чтобы он являлся ресурсом, позволяющим мобилизовать благоприятные и нивелировать неблагоприятные для успешности обучения индивидуально-психологические особенности путём создания компенсаторных отношений между высоко и низко развитыми стилевыми особенностями за счет высокой субъектной активности и положительного отношения к учению [11].

Так каково же соотношение СР и ПК? И что в их взаимосвязи выступает в роли ресурса, а что может рассматриваться как потенциал? Возможно ли предположить, что компоненты ПК и саморегуляцию связывают реципрокные отношения? В одних случаях, компоненты ПК (самоэффективность, оптимизм и пр.) могут быть значимым ресурсом эффективной саморегуляции, в других ситуациях, наоборот - саморегуляция актуализирует компоненты ПК человека для достижения цели.

Концепция человеческого капитала (Human Capital) изначально cформулирована в экономическом контексте, которую предложил Теодор Шульц [35], указывая на необходимость обоснования преимуществ инвестирования в образование в национальном масштабе [39]. В современном проекте Всемирного банка по оценки индекса ЧК отмечена более широкая интерпретация его составляющих, которые включают все затраты произведённые в течение жизни (семья, образовательные учреждения, культура, организации и государство) [41]. И.А. Майбурова (2003) указывает на оформившиеся основные две позиции определения ЧК, в соответствии с первым технократическим подходом, человек сам по себе является капиталом. А во втором, научном подходе, где не наблюдается единства в понимании категории ЧК говорится, что капиталом является не сам человек, а совокупность приоб- 
ретённых и унаследованных им способностей [9]. Анализ исследований оценки ЧК свидетельствуют о том, что при этом в основном используются экономические и социальные параметры. Юрьев А.И. указывает на то, что при наличии высоких показателей индекса развития человеческого потенциала возможно эфффективное использование всех ресурсов. А это требует соответствующего интегрального показателя качества человеческого капитала, который формируется на основании уровня развития психологических характеристик человека (перцептивных, когнитивных, личностных и эмоциональных) [19].

В последующем границы человеческого и социального капитала расширились за счет выделения нематериального конструкта, а именно, позитивного психологического капитала, и предложено следующее его понимание: «.... человеческий капитал - это просто «то, что вы знаете», тогда как социальный капитал - это «кого вы знаете» [27, с.46]. Эти исследования показали, что самоэффрективность, оптимизм, видение перспективы и жизнестойкость являются компонентами психологического капитала, который положительно связан с эфффективностью деятельности и активностью поведения в стрессовой ситуации. Последнее свойство непосредственно связано со стабильностью поведения человека в стрессогенных условиях, а, следовательно, однозначно отсылает нас к надёжности осознанной саморегуляции. Исследования, получившие широкую известность, рассматривают психологический капитал в контексте производительности труда, психологического благополучия и удовлетворённости трудом. При этом подчёркивается, что психологический капитал может наращиваться и убывать, то есть подвержен динамике [27, 28]. А это утверждение, в свою очередь, укладывается в контекст ресурсного подхода.

Психологический капитал (РsyCap) - это позитивное психологическое состояние развития индивида, характеризующееся: (1) уверенностью в себе и своих усилиях при выполнении сложных заданий; (2) позитивным отношением к успеху сейчас и в будущем; (3) настойчивостью в достижении цели и, когда это необходимо, изменением путей без изменения цели; и (4) способностью при столкновении с проблемами и невзгодами, поддержать себя и даже на время вернуться назад для достижения успеха в будущем. Это определение возникло в рамках позитивной психологии и разрабатывалось для организаций. Появившаяся в начале 21 века концепция, предложила руководителям организаций новый подход достижения конкурентных преимуществ. Если ранее профессиональный отбор исходил из знаний, навыков, умений и опыта, то теперь Фред Лютанс призвал сосредоточить внимание на психологических свойствах, которые являются индивидуальными, уникальными, кумулятивными и непередаваемыми конкурентам, как, к примеру, материальные или фринансовые [27]. Для измерения РsyСар было разработано несколько шкал. Оригинальной шкалой, разработанной Лютансом, Юсефом и Аволио (2007) в 
контексте организаций, является опросник психологического капитала 24 (PCQ24). Оцениваются четыре показателя: надежда, самоэффрективность, устойчивость и оптимизм. Концепция Р syCap стала еще более актуальной в связи с недавними открытиями в области нейропластичности. Благодаря этому свойству, РsyСар можно развивать и укреплять.

Далее проанализируем исследования ресурсной природы психологического капитала. Исследования ПК, очевидно, выявляют его ресурсную роль по отношению к различным проявлениям субъектной активности человека и успешности реализации его деятельности. Результаты мета-анализа исследований о влияния ПК на эффективность деятельности и удовлетворенности работой свидетельствует о его значимой роли в их прогнозировании [21]. Устойчиво воспроизводится на выборках работников различных сфер взаимосвязь ПК С производительностью [33, 38]; психологическим благополучием [20, 24, 26], социальными отношениями [28], увлечённостью работой [16, 35]. ПК выступает медиатором взаимосвязи выгорания и результативности, выступая буфером, нейтрализующим негативные эффекты рабочего стресса [36]. Однако, применительно к образовательной сфере исследования ПК практически не проводились. Исследователи отмечают, что есть все предпосылки изучения ПК на до профрессиональном уровне. Немногочисленные исследования в этой области обосновывают возможность считать ПК ключевым элементом успеваемости, академической мотивации, психологического благополучия студентов [25, 37, 40].

В числе актуальных направлений изучения ПК учёные обозначают проблему раскрытия основных механизмов, посредством которых ПК оказывает влияние на результаты деятельности. А. Невман отмечает, что существует потребность в рассмотрении специфических особенностей целедостижения и саморегуляции у людей с различным уровнем ПК [32].

Можно заключить, что ресурсный подход к психологическому капиталу и осознанной саморегуляции человека позволяет обозначить перспективные направления, связанные с раскрытием регуляторных механизмов актуализации ресурсов ПК личности для достижения целей в разнообразных видах его деятельности.

\section{Выводы}

1. Ресурсный подход к психологическому капиталу позволяет рассматривать его как личностный потенциал резервных свойств, отношений и состояний, накопленных в опыте человека, которые могут осознаваться $и$ актуализироваться с помощью системы ресурсов осознанной саморегуляции при определенных условиях, в частности при выполнении сложных и нестандартных заданий. 
2. Осознанная саморегуляция является метасистемой универсальных и специальных ресурсов человека, позволяющих вносить вклад в продуктивные аспекты достижения целей, а также активизировать резервы психологического капитала для достижения разнообразных задач жизнедеятельности.

3. Перспективным направлением эмпирических исследований может стать изучение как совместного, так и опосредствующего вклада осознанной саморегуляции и в различные показатели успешности, вовлеченности и психологического благополучия.

\section{Литература}

1. Аванесян Г.М. Психологические механизмы биологической обратной связи в эксперименте, моделирующем деятельность спортсмена// Вестник МАНЭБ, СПБ, т. 9, N 3, Ереван, 2004, с. 172-175

2. Бодров В.А. Психологический стресс: природа и преодоление / В.А. Бодров. - М.: ПЕР СЭ, 2006. - 528 с.

3. Водопьянова Н.Е. Современные концепции ресурсов субъекта профессиональной деятельности // Вестник Санкт-Петербургского университета. Психология. - 2015. - №. 1. Сер. 16. 2015. Вып. 1. с. 45-54.

4. Кондратюк Н.Г., Моросанова В.И. Диффреренциально-регуляторные основы надёжности действий профессионалов//Акмеология. Научнопрактический журнал. 2012, № 4 (44). с. 68-74.

5. Конопкин О.А. Психологические механизмы регуляции деятельности // Предисл. В.И. Моросановой. М.: ЛЕНАНД, 2011. - 320 с.

6. Круглова Н.Ф. Экспресс-диагностика и коррекция регуляторно-когнитивной структуры учебной деятельности подростков. М.: ПИ РАО, Экопсихологический центр развития образоват. и социал. систем, 2000, 110с.

7. Леонова А.Б. Психическая надежность профессионала и современные технологии управления стрессом // Вестник Московского университета. Серия 14: Психология. 2007. № 3. с.. 69-81.

8. Леонтьев Д.А. Саморегуляция, ресурсы и личностный потенциал // Сибирский психологический журнал. 2016. №. 62. с. 18-37.

9. Майбуров И.А. Вклад человеческого капитала в экономическое развитие России//Экономическая наука современной России, №4, 2003. c.54-69

10. Моросанова В.И. Диффреренциальный подход к психической саморегуляции и его применение $\mathrm{k}$ исследованию действий профессионала // Психологический журнал 2012- том 33 - № 3. с. 98111. 
11. Моросанова В.И. Осознанная саморегуляция человека как психологический ресурс достижения учебных и профессиональных целей / Теоретическая и экспериментальная психология. 2014. №4. c.16-38.

12. Моросанова В.И. Осознанная саморегуляция как метасистема психологических ресурсов достижения целей и саморазвития человека // Фундаментальные и прикладные исследования современной психологии: результаты и перспективы развития / - М.: Изд-во «Институт психологии РАН», 2017. с. 501-509.

13. Моросанова В.И., Фомина Т.Г., Ковас Ю.В., Богданова О.Е. Регуляторные и когнитивные предикторы математической успешности школьников // Психологический журнал. 2014. №4. с. 35-46.

14. Моросанова В.И., Филиппова Е.В. От чего зависит надежность действий учащихся на экзамене // Вопросы психологии, 2019, №1. с. 65-78.

15. Мандрикова Е. Ю., Горбунова А. А. Взаимосвязь увлеченности работой, личностных ресурсов и удовлетворенности трудом сотрудников // Организационная психология. 2012. Т. 2. №. 4. с.2-22

16. Обознов А.А. Психическая регуляция операторской деятельности в особых условиях: дис. д-ра психол. наук: 19.00.03, М: ИП РАН, 2003.

17. Фомина Т.Г., Моросанова В.И. Профессиональное выгорание учителя: регуляторный подход / Т.Г. Фомина, В.И. Моросанова // Акмеология. №3(47). 2013. с. 40-44

18. Хазова С.А., Дорьева Е.А. Ресурсы субъекта: теория и практика исследования. Кострома, КГУ им. Н.А. Некрасова, 2012. 250с.

19. Avey, J. B., Luthans, F., Smith, R. M., \& Palmer, N. F. Impact of positive psychological capital on employee well-being over time //Journal of occupational health psychology. - 2010. 15(1). p. 17-28.

20. Avey, J. B., Reichard, R. J., Luthans, F., Mhatre, K. H. Meta-analysis of the impact of positive psychological capital on employee attitudes, behaviors, and performance //Human resource development quarterly. 2011. 22. №. 2.p. 127-152.

21. Baumeister, R. F., Vohs, K. D., \& Tice, D. M. (2007). The strength model of self-control. Current Directions In Psychological Science, 16(6), 351-355

22. Cheung F., Tang C. S., Tang S. Psychological capital as a moderator between emotional labor, burnout, and job satisfaction among school teachers in China // International Journal of Stress Management. 2011. 18. №. 4. p. 348. 
23. Culbertson S. S., Fullagar C. J., Mills M. J. Feeling good and doing great: The relationship between psychological capital and well-being //Journal of occupational health psychology. 2010. vol. 15. №. 4. p. 421.

24. Datu J. A. D., King R. B., Valdez J. P. M. Psychological capital bolsters motivation, engagement, and achievement: Cross-sectional and longitudinal studies // The Journal of Positive Psychology. 2018. 13(3). p. 260-270.

25. Li B., Ma, H., Guo, Y., Xu, F., Yu, F., Zhou, Z. Positive psychological capital: A new approach to social support and subjective well-being // Social Behavior and Personality: an international journal. 2014. 42(1). p. 135-144.

26. Luthans F., Luthans K. W., Luthans B. C., Positive psychological capital: Beyond human and social capital// Business Horizons 47/1 JanuaryFebruary 2004, pp. 45-50

27. Luthans F. Norman, S. M., Avolio, B. J., Avey, J. B.The mediating role of psychological capital in the supportive organizational climateemployee performance relationship // Journal of Organizational Behavior: The Intern. Journal of Industrial, Occupational and Organizational Psychology and Behavior. 2008. 29(2). p. 219-238.

28. Morosanova V.I., Fomina T.G., Bondarenko I.N. (2015) Academic achievement: Intelligence, regulatory, and cognitive predictors // Psychology in Russia: State of the Art, 8(3), 136-157.

29. Morosanova, V.I., Fomina, T.G., Kovas, Y.V. Bogdanova, O.E. Cognitive and regulatory characteristics and mathematical performance in high school students // Personality and Individual Differences (2016), pp. 177-186.

30. Morosanova V.I., Gaidamashko I.V., Chistyakova S.N., Kondratyuk N.G., Burmistrova-Savenkova A.V. Regulatory and personality predictors of the reliability of professional actions// Psychology in Russia: State of the Art. 2017. Vol.10, N 4. P.195-207.

31. Newman, A., Ucbasaran, D., Zhu, F. E. I., Hirst, G. Newman A. et al. Psychological capital: A review and synthesis//Journal of Organizational Behavior. 2014. 35. №. S1. p. 120-S138.

32. Peterson, S. J., Luthans, F., Avolio, B. J., Walumbwa, F. O., \& Zhang, Z. Psychological capital and employee performance: A latent growth modeling approach // Personnel psychology. 2011. 64(2). p. 427-450.

33. Pintrich, P.R. \& De Groot E. (1990). Motivational and self-regulated learning components of classroom academic performance. Journal of Educational Psychology, 82(1), pp. 33-50. 
34. Roberts S. J., Scherer L. L., Bowyer C. J. Job stress and incivility: What role does psychological capital play?//Journal of Leadership \& Organizational Studies. 2011. 18(4). p. 449-458.

35. Schultz T. W. Investment in Human Capital//The American Economic Review, Vol. 51, No. 1 (Mar., 1961), pp. 1-17, p.2.

36. Siu O. L., Bakker A. B., Jiang X. Psychological capital among university students: Relationships with study engagement and intrinsic motivation //Journal of Happiness Studies. 2014. 15(4). p. 979-994.

37. Sun, T., Zhao, X. W., Yang, L. B., \& Fan, L. H. (2012). The impact of psychological capital on job embeddedness and job performance among nurses: a structural equation approach. Journal of Advanced Nursing, 68, 69-79.

38. Sweetman D., Luthans F. The power of positive psychology: Psychological capital and work engagement //Work engagement: A handbook of essential theory and research. 2010. p. 54-68.

39. Vanno V., Kaemkate W., Wongwanich S. Relationships between academic performance, perceived group psychological capital, and positive psychological capital of Thai undergraduate students //ProcediaSocial and Behavioral Sciences.2014. vol. 116. P.3226-3230.

40. Winne, P. H. (1995). Self-regulation is ubiquitous but its forms vary with knowledge. Educational Psychologist, 30(4), p.223-228.

41. https://www.worldbank.org/en/publication/human-capital//Human Capital Project.

\section{RESOURCE APPROACH TO PSYCHOLOGICAL CAPITAL AND HUMAN'S CONSCIOUS SELF-REGULATION}

Morosanova V.I. (FGBNU "Psychological Institute of the Russian

Academy of Education”, Moscow, Russia)

Avanesyan H. M. (Yerevan State University, Yerevan, Armenia)

The article is devoted to a resource approach to the study of psychological capital and conscious human self-regulation. Its main provisions were formulated earlier (V.I. Morosanova, 2014, 2017, 2019), and this article aims to reveal the resource nature of these phenomena, which are most important for achieving professional and educational goals. In the context of the problem, the main aspects of the study of psychological capital are analyzed. It is concluded that conscious self-regulation is a metasystem of universal and special resources of a person that allows contributing to the productive aspects of achieving goals, as well as activating the reserves of psychological capital to achieve various vital functions. 
Key words: psychological capital, resource approach, self-recognized selfregulation, educational, professional activity.

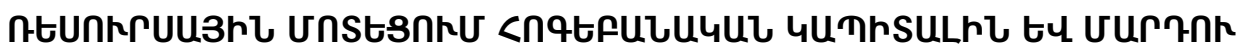

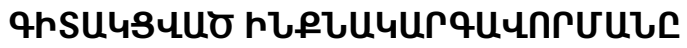

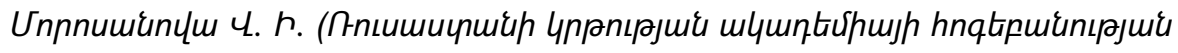

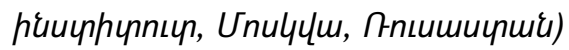

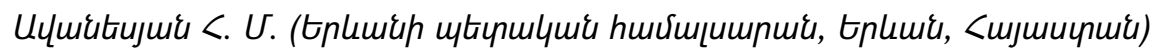

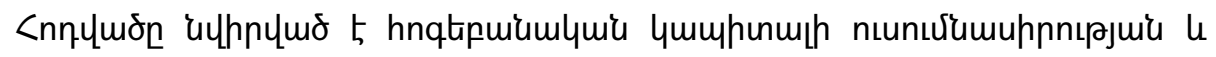

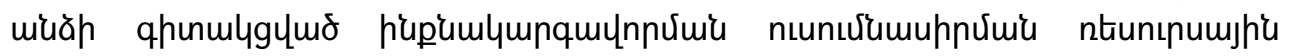

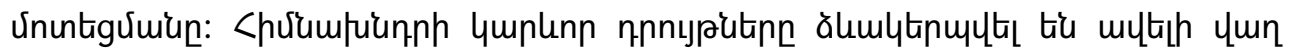

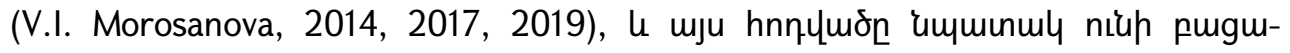

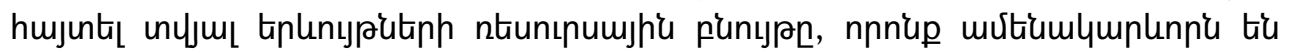

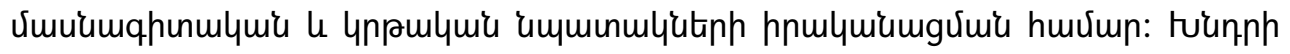

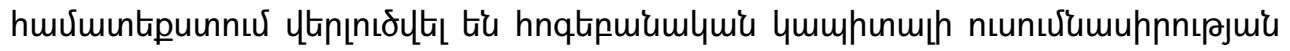

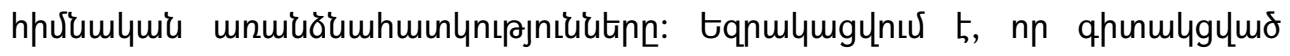

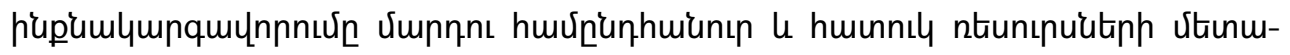

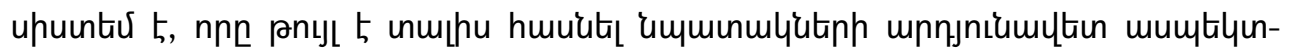

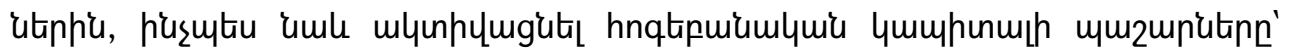

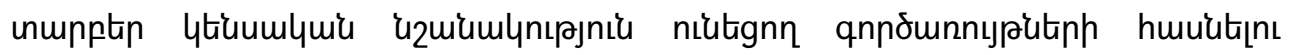
huvium:

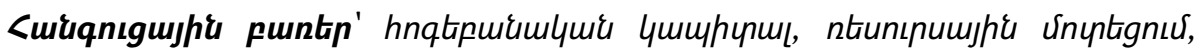

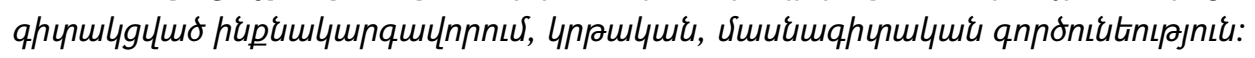

